disorder. The appendix makes no pretence to being exhaustive on the various syndromes but it is nevertheless of value when read in conjunction with New Chromosomal Syndromes by Yunis and Atlas of Chromosomal Syndromes by de Grouchy. A directory of this sort is obviously not a book to be read from cover to cover, but the information it contains should ensure it a place in all self-respecting cytogenetics units.

K M LAURENCE AND Peter Gregory

\section{Counseling in Medical Genetics}

3rd edition. By Sheldon Reed. (Pp ix +245 ; figures + tables.) New York: Alan R Liss. 1980.

The third edition of a treatise on genetic counselling by one who not only pioneered the activity but also invented the name for it must be approached with respect. Dr Reed is a $\mathrm{PhD}$ genetic counsellor, a creature far rarer in this country than in the USA. His book is written for 'family physicians', and seems designed more to give them some insight into what genetic counselling is about than to help them to do it themselves. Indeed, the author sees no likelihood of American 'family physicians' satisfying much of the increasing demand for genetic counselling, apparently because they simply cannot afford to spend up to an hour with one family. In Britain, most clinical geneticists would hope that the training of general practitioners and hospital specialists will enable them increasingly to deal with the genetic counselling aspects of the commoner clinical problems they encounter, as suggested by Professor P S Harper in his recent book Practical Genetic Counselling. That this should seem impossible in the USA is a sad comment on their privately based fee for service medical system.

Dr Reed acknowledges that non-medical genetic counsellors must rely on the diagnosis provided by the referring physician, and he clearly expects his non-medical counselling colleagues to develop their own feel for a shaky diagnosis or a case requiring further investigation. But he does not explore other potential difficulties, such as the clinical problem that may arise unexpectedly during a consultation, or the frequent need to discuss with prospective parents details of treatment and prognosis of a condition.

The book begins with three pleasantly personal chapters, the longest of which, 'A Philosophy for Counselling', contains much wisdom and experience. There follow chapters on chromosome anomalies, prenatal diagnosis, treatment of genetic disorders, and Mendelian inheritance, in that order. The remaining chapters cover the genetics of common $\stackrel{\odot}{\frac{1}{9}}$ clinical problems such as cystic fibrosis, mental $\stackrel{\oplus}{\rightarrow}$ retardation, the psychoses, congenital malforma- $\vec{F}$ tions, epilepsy, and diabetes. In addition, an $\stackrel{5}{+}$ unusually high proportion of space is devoted to medically less specific topics such as consanguinity, $\frac{\overline{\bar{D}}}{\overline{\mathrm{D}}}$ drug and radiation exposure during pregnancy, $\frac{D}{\overrightarrow{0}}$ paternity testing, twins, and the inheritance of $\propto$ normal traits.

The book consists largely of continuous prose, $\vec{\bullet}$ with very few diagrams, tables, or illustrations. This, and the rather idiosyncratic order of presenta- $\vec{\omega}$ tion, makes quick reference to specific topics $\stackrel{\circ}{S}$ difficult. In some of the longer sections dealing with specific disorders family study data are quoted, but $\stackrel{0}{\circ}$ the author fails to assimilate these and present his own critical view of the situation. There is an exten- iv sive bibliography, the most useful part of the book $\omega_{\infty}^{\omega}$ to clinical geneticists, who will find many familiar o

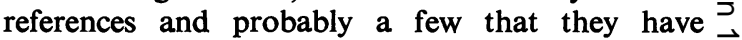
overlooked. The literary style is quirky and collo- $\vec{c}$ quial, often refreshingly so, but many will be irritated by such sentences as "The bottom line is that drinking and/or smoking are no-nos for women who $\vec{\emptyset}$ are pregnant or likely to become so".

The main drawback of this book in this reviewer's opinion is the rather frequent occurrence of small inconsistencies, statements with which one could quibble, and passages which could confuse or mislead the inexperienced. For example, although the $\mathbb{\otimes}$ author states on page 45 that "non-banding tech- $\stackrel{2}{\Rightarrow}$ niques are completely outmoded", fig 3 appears to $\frac{0}{3}$ show an unbanded karyotype. On page 43 , the discussion switches without warning from a 13;14 translocation to one involving a chromosome 21 . On page 46, chronic myelogenous leukaemia is confusingly introduced at the tail end of a section on chromosome anomalies. There are inconsistencies 3 . between two discussions of the recurrence risk of $\delta$ trisomy 21 on pages 30 and 49 . On page 67 , the 3 author seems to assume that multifactorial traits are necessarily heterogeneous. On the same page, a discussion of the diagnosis of autosomal dominant traits by means of linked markers omits to mention that linkage relationships in a given family may be $\mathcal{N}$ unsuitable. On page 68 , quoting work on the bias $N$ which may enter estimates of heterozygote fertility N in recessive disorders, the author gives the impression that it is heterozygote frequency that may be falsely overestimated. On page 85 , the conclusion that HLA-B27 positive relatives of index patients with ankylosing spondylitis have an $80 \%$ risk of the disease does not follow from the population data quoted. On page 86 , it is implied that the polymorphism of the HLA region makes it of outstanding $\stackrel{\odot}{\oplus}$ value for the diagnosis of twin zygosity. On page 96, 
in a discussion of the prognosis of cystic fibrosis, the example quoted of athleticism in a patient with Schwachman's disease "a disease similar to CF" is misleading. In the chapter on multifactorial inheritance the concept of heritability is repeatedly invoked without any explanation of its precise meaning. On page 106, a high heritability is taken to indicate resistance of a trait to environmental manipulations; however, a trait with $100 \%$ heritability may be entirely prevented by new environments which were not operating when the heritability was estimated. On pages 172 and 173, conflicting patterns of multifactorial inheritance are presented without explanation. On the one hand, "The offspring of two very short persons should be taller than both their parents" because of "Galton's law of regression towards the mean", but on the next page, "the body build indices of the progeny ... are exactly intermediate between those of their parents" indicating "multigenic inheritance". Both statements could be true, but without additional explanation this could be puzzling.

In conclusion, this is a book to be read straight through by newcomers to genetic counselling who have some knowledge of medicine. They will find many useful insights and suggestions for further reading, but they may need guidance in places from a more experienced colleague.

N R DENNIS

\section{Genetic Engineering 2}

Edited by Robert Williamson. (Pp xii +204; figures + tables. $£ 9.80, \$ 24.00$.) London, New York: Academic Press. 1981.

Genetic Engineering 1 (reviewed in the April 1982 issue) set a high standard for this series, with substantial up to date contributions from leading researchers in the field. Genetic Engineering 2 is even better.

The contributions in both books are sufficiently detailed to be useful to scientists actively involved in recombinant DNA techniques at the bench, but it would be wrong to imagine that these scientists are the only people who would benefit from reading these books. The present reviewer is one of a large and growing number of people who, although not involved at the bench, is nevertheless concerned with the application of recombinant DNA techniques in his own particular field. For these people Genetic Engineering 2 makes a better introduction than book 1 , for the former starts with an excellent 40 page paper on 'Recent Studies of Gene Evolution using Recombinant DNA' by Dr Jeffreys. This sets the scene perfectly for an 80 page account on the
'Use of Genomic Libraries for the Isolation and Study of Eukaryotic Genes' by Dahl, Flavell, and Grosveld. These two papers, together with Dr Malcolm's discussion of the use of restriction enzymes (the starting point for the DNA revolution), provide an admirable way into the field for those who have grasped the general principles but are frustrated by the lack of clear account of the practical details. The book finishes with a paper on 'Gene Cloning in Yeast' by Dr Beggs.

This book is strongly recommended to anyone with a simple basic knowledge of molecular biology who has an interest in genetic engineering and its application. I can't wait for book 3 !

\section{E Pembrey}

\section{DNA Repair and Mutagenesis in Eukaryotes}

Basic Life Sciences vol 15. Edited by W M Generoso, $M$ D Shelby, and F J de Serres. (Pp xii +458; figures + -tables. \$49.50). New York: Plenum Press. 1980.

This volume consists of the proceedings of a symposium on 'DNA Repair and Mutagenesis in Eukaryotes', which took place in Atlanta in June 1979 under the sponsorship of the National Institute of Environmental Health Sciences. It contains 31 contributions, divided into six sections. The first of these sections sets the stage with three reviews: one by Kimball on the relationship between repair processes and mutation induction in bacteria; one by Straus et al on the modification, by cellular systems, of the response to chemical mutagens (this mainly reports recent work from the authors' laboratory); and, finally, one by Setlow on DNA repair pathways, with emphasis on excision repair. The other five sections deal, in order, with data on lower eukaryotes, Drosophila, mammalian somatic cells, mouse germ cells, and human health hazard assessment. Each one of these sections ends with a summary chapter, which guides the reader through the material of the book.

The second section is subdivided into two parts. The first consists of three chapters by Schroeder and Olson, Fraser et al, and de Serres on the characteristics of mutants of Neurospora crassa sensitive to mutagens, and the effects of such inherited mutations on mutation induction. The second has five contributions (including the summary chapter by Brockman) on Saccharomyces cerevisiae. Here papers by Lemontt, Reynolds and Friedberg, Prakash and Prakash, and von Borstel and Hastings on DNA repair and mutagenesis reveal differences and similarities between such processes in bacteria and yeast. 